\title{
Adverse events related to herbal products used by patients presenting at emergency departments
}

\section{Sunanta Tangnitipong ${ }^{1}$, Supat Jiranusornkul' , Pathomwat Wongrattanakamon ${ }^{2}$}

${ }^{1}$ School of Public Health, University of Phayao, Thailand

${ }^{2}$ Faculty of Pharmacy, Chiang Mai University, Thailand

\begin{abstract}
Herbal medications are gaining popularity in many countries. Although most can be used without any problem, serious toxicities do occur. Adverse events can be anticipated when herbal medications are used at excessive dose, long-term, for non-approved indications or by patients who are using multiple medications. Adverse events should be anticipated when these herbal medications with identified pharmacological effects or toxic ingredients are used. Healthcare professionals need to discuss or advise patients regarding their use. Physician-obtained medication histories towards specific herbal product use could provide relevant pharmacologic information and uncover cases of adverse events or toxicity from the used herbal products.
\end{abstract}

Keywords: Adverse events · Emergency · Herbs · Toxicity · Traditional use

\section{Citation}

Tangnitipong S, Jiranusornkul S, Wongrattanakamon P. Adverse events related to herbal products used by patients presenting at emergency departments. Eur J Transl Clin Med. 2021;4(2):101-106.

DOI: $10.31373 /$ ejtcm/142816

\section{Introduction}

Herbal medicines, also called phytomedicines, consist in the use of plants or plant extracts for medicinal purposes. Medicinal plant products include raw or processed plant parts such as roots, stems, leaves, flowers, and seeds [1]. Many Asian, African, and Pacific people utilize traditional medicine as primary health care [2-5]. In Thailand, particular in rural areas, where access to medical treatments with a Western approach may be expensive or simply not 
available. Thai herbs are available for collection from many areas. Preparation of the medicinal plants for remedy such as tea, tincture or filtrate is inexpensive and can be practiced with a minimal amount of training. Therefore, for utilization in primary health care, a herbal medicine may hold great promise [6].

Many Thai people receive Thai traditional medicine including herbal medicines, herbal steam bath, acupuncture, and traditional massage. Traditional healers, including herbal, massage, and spiritual healers as well as traditional midwives, are distributed all over Thailand [7]. The Thai government has been supporting an endeavor to systematically develop Thai herbal medicines and medicinal plant products. As part of a vigorous attempt to advocate the utilize of herbal medicines/medicinal plant products and serve diversity of alternatives for primary health care or to Western medicines, some medicinal plant products have been placed on the National List of Essential Medicines [8].

All of these Thai medicinal plants provide a lot of pharmacological effects. Even though many of these products are used safely, but not all of them have adequate clinical research to advocate the use [8]. Despite extensive uses of medicinal plant formulations along with their benefits, these formulations are not fully safe. The indiscriminate or non-regulated utilize of the medicinal plant products may put consumers' health at risk of toxicity. Moreover, there is limited scientific evidence regarding evaluation of clinical safety and effectiveness of medicine plant formulas. Adverse reactions to medicinal plants have been noted when utilized alone or in combination with conventional medicines. The aim of this study is to summarize the literature regarding the adverse events related to specific herbal medications requiring emergency department visits.

\section{Materials and methods}

This is a narrative type of review. Independent English-language literature search was done by all authors during December 2020, using PubMed, Web of Science, Scopus and Google Scholar with no limitation on the year of publish. We used the keywords "emergency department," in addition with the following condition-specific terms: botanicals, complementary and alternative medicine, diseases, herbal medicine, medicinal plants, patients, admitted, traditional use, treatment, side effects, and adverse effects/ events. A detailed cross-review of references was also carried out. Exclusion criteria were: reports of non-emergency cases, conventional medications, and adverse events not involving herbal medications. No statistical calculations were performed due to the narrative format of this review.

\section{Results}

Over 100 articles were retrieved in the search, 37 of the articles met the criteria and 13 of those were included in this analysis. The adverse effects which were most commonly noticed in the analysis were neurological adverse effects including delirium, encephalopathy and neuropathy and seizures.

\section{Photosensitivity rash}

Photosensitivity is an occasional adverse event related to herbal medicine utilization [9]. St. John's wort was most regularly implicated case reports in the literature. One case report was found describing emergency department treatment of hypertension due to use of a multi-herbal formula. Palanisamy et al. [10], reported a case of pruritic, erythematous rash on the sunexposed surfaces of the patient's neck and extremities after taking a dietary supplement product containing various herbs including ginseng, goldenseal and bee pollen. Although cases of photosensitivity due to the individual components in this supplement have not been reported, it is possible that this toxic reaction may caused by interactions among the ingredients. Therefore, the combining of multiple herbs/ingredients into one single formulation should be cautioned [10].

\section{Hypertension}

With long-term use, ginseng may cause hypertension $[9,11]$. Siegel [12] described emergency department treatment of hypertension due to excess use of ginseng herb. The author also described the major stimulant effects of ginseng and indicated that long-term use resulted in ginseng abuse syndrome which can be associated with hypertension. Symptoms of central nervous system excitation and arousal occurred with most subjects. Such effects are probably due to the dammarenetriol glycosides found in ginseng that have strong central nervous system excitatory actions. Moreover, some of ginseng's components have a molecular structure similar to the digitalis glycosides [12].

\section{Hypokalemia}

Liquorice is a particular example of the herbal product that causes hypokalemia $[9,13]$. Liquorice is a medicinal plant product produce from the dried roots and rhizomes of the plants, such as, from Glycyrrhiza species; G. inflate, G. uralensis, and G. glabra are regularly utilized as traditional medicines for cough, eliminating phlegm, tonifying the spleen and stomach, supplement the vital energy and alleviating pain. Moreover, it is also utilized as a flavoring agent, health food and snack [14]. If used long-term and in large quantities, liquorice exhibits a mineralocorticoid effect that 
may result in severe depletion of potassium stores in the entire body [15]. Two case reports (in 2 articles) were found describing emergency department treatment of hypokalemia due to excess use of liquorice. The first report described a patient with symptoms of bradycardia and hypotension [15]. Systematic investigation revealed that the patient suffered from constipation for a number of months, therefore on a daily basis she patient took large quantities of liquorice for its laxative effect. Hypokalemia secondary to liquorice overindulgence was diagnosed this patient. Such cause of hypokalemia is rare, however every emergency health care provider should be mindful of herbal product use as a possible cause of hypokalemic cardiac arrest [15]. The second report concerned an emergency department patient with ventricular fibrillation and medical history of liquorice intake for some medical proposes [16]. After stopping liquorice intake, potassium replacement was given resulting in a progressive change of the Brugada-like electrocardiographic pattern. This case report shows the importance of medical history-taking at emergency departments regarding herbal product use in patients with electrolyte abnormalities. Moreover, emergency care providers should be aware of the potential role of hypokalemia in inducing a life-threatening arrhythmia in patients with Brugada syndrome [16].

\section{Neurological adverse effects}

Some serious neurological adverse effects can be caused by herbal medications. Numerous case reports reveal various central nervous system adverse effects including cerebral arteritis, cerebral edema, coma, confusion, delirium, encephalopathy, hallucinations, intracerebral hemorrhage or mood disturbances. In addition, other cerebrovascular disorders and peripheral neurological disorders including movement disorders, muscle weakness, paresthesiae as well as seizures. They result from improper utilization, toxicity of herbal constituents, adulteration or contamination of herbal preparations as well as herb-drug interactions [17].

\section{Delirium}

Traditional medicine adulterated or contaminated with toxic plants, conventional drugs as well as heavy metals are major health hazards for herbal product consumers. One case of delirium due to contaminated Strobilanthes forrestii Diels was reported by Shea et al. [18]. One hour after taking the herbal tea, a mixup between Cyathula officinalis Kuan (extensively utilized in a traditional medicine for the treatment of inflammatory disorders [19]) and S. forrestii (commonly used as an adulterant [20]), the patient presented slurred speech, disorientation, visual hallucination (central anticholinergic toxicity), clumsiness in all four limbs and generalized weakness (peripheral anticholinergic toxicity). It was found that $S$. forrestii was incorrectly prescribed (due to the similar local nomenclature of both plants) and contaminated with tropane alkaloids including atropine, scopolamine and anisodamine during the manufacturing process. The clinical presentation pointed out the anti-cholinergic toxicity of tropane alkaloids [18]. Frequent monitoring and surveying of medicinal plant products for undeclared ingredients or potentially toxic adulterants are very necessary and the use of these substances should be strictly legislated.

\section{Encephalopathy and neuropathy}

Two case reports from two different studies were found describing emergency department treatment of encephalopathy and neuropathy due to the use of some herbs. The first case regarding traditional medicine contaminated with a toxic plant have also been reported by $\mathrm{Ng}$ et al. [21]. The two patients developed intoxication caused by podophyllin after intake of a broth of guijiu, the root preparation of the plant Podophyllum emodi Wall. The neurological manifestations in both patients as well as the pathology of peripheral neuropathy were seen. The decoction prepared from the herbal formulation longdancao was intended to have been prepared for both patients. The roots of Gentiana species; G. manschurica, G. scabra, G. triflora, and $G$. rigescens are officially accepted as plant parts used for this herbal formulation. Many importers and retailers have been mistaking guijiu for longdancao due to their apparent similarity in morphology. Guijiu is prepared from the root of $P$. emodi, (also known as $P$. emodi Wall var. chinensis Sprague and Sinopodophyllum emodi (Wall). Ying) which contains podophyllotoxin, demethylpodophyllotoxin, demethyldeoxypodophyllotoxin, deoxypodophyllotoxin, diphyllin, sikkimotoxin, as well as flavonoids kaempferol and quercetin. Use of Guijiu as an adulterant of longdancao should be considered as a safety issue. Regarding the clinical manifestation of podophyllin neurotoxicity, cerebral involvement leads to acute alteration of sensorium, which ranges from mild confusion to frank coma and higher mental function impairment which is permanent. The described patients suffered severe encephalopathy. Podophyllotoxin, a lipid-soluble molecule that crosses cell membranes with ease, was speculated to be the toxic compound responsible. Colchicine and podophyllotoxin are structurally related resulting in colchicine-like effect (similar clinical effects regarding arresting the mitotic spindle) of this compound and its derivatives. In vitro ability to bind to microtubular protein and inhibit axoplasmic flow may lead to neurotoxicity of podophyllotoxin [21].

The second set of cases was reported by Yang et al. and involved peripheral neuropathy, probably induced by tartarian buckwheat products that have been using as a hypoglycemic health food [22]. Tartarian buckwheat (Fagopyrum ta- 
taricum (L.) Gaertn.) is used to prepare the buckwheat black tea composite tablets. Its seed contains high-quality proteins which provide essential amino acids. Flavonoids are the major active components of this medicinal plant and they are considered to possess hypoglycemic, antioxidant, antiaging, lipid-lowering, anti-atherosclerosis, immunity-enhancing, sterilizing, anti-mutagenic and anticancer activities. Although various forms of neurotoxicity caused by herbs were documented, case reports regarding tartarian buckwheat poisoning are rare. Yang et al reported new-onset polyneuropathy with dyskinesia in five male patients prospectively induced by recent use of $F$. tataricum products as a diabetes remedy. All the cases indicated that products prepared from $F$. $t a$ taricum may lead to toxic peripheral nerve lesion. Therefore, better regulation and close monitoring of consumption of tartarian buckwheat products are needed [22].

\section{Seizures}

Camphor has been used for centuries for multiple purposes. Currently it is freely available widely used in many Asian countries. In Ayurvedic traditions, camphor is used orally for sinusitis, flatulence, circulatory problems, joint pain, painful menstruation, epilepsy, gout, as a lactation suppressant and as an analeptic. Externally, it is used for chapped lips and cold sores, as muscle and joint liniment and as an inhalant for respiratory disorders. Mackinney et al reported the case of the patient who intentionally ingested approximately $10 \mathrm{~g}$ of pure camphor for purported medical purposes has been reported by [23]. This patient had a history of nasal allergies and consequently used locally a small amount of produced pure camphor crystals to clear the nasal passages. Moreover, the patient consumed a heaping teaspoon of loose camphor crystals (on the day of admission) for purpose of digestion improvement. A few hours later, the patient developed abdominal pain and nausea, palpitations and confusion, headache, followed by two grand mal seizures and admission to an emergency department. Camphor is rapidly absorbed in the gastrointestinal tract (found in the blood within minutes) as well as through the skin and via inhalation. Large ingestions generally result in nausea, vomiting and mucosal irritation within
5 to 15 minutes, along with tonic-clonic convulsions, which often are the first sign of intoxication. Finding the cause of new-onset seizures is often challenging for emergency health care providers and neurologists, therefore careful history taking is essential, including questions about the use of herbal medications and supplements [23].

\section{Discussion}

As herbal product use has become more common, patients are likely to be using these products alongside conventional medication or even instead of it. Healthcare professionals need to be aware of herbal products' adverse effects and interactions with conventional medication. Many studies showed that patients often do not wish to inform their healthcare professionals regarding herbal product use, therefore such information is not available in their medical records [24]. The reports of photosensitivity rash, hypertension, hypokalemia, and neurological adverse effects related to concurrent multi-herbal formula, ginseng, liquorice, adulterants, tartarian buckwheat and camphor use are a reminder of the importance of investigation of patients' herbal product use.

\section{Conclusion}

Herbal medications play an important role in the general health care of people in many countries worldwide. Most of herbal medications can be used safely and healthcare professionals need to discuss or advise patients regarding their use. Adverse effects or toxicities can arise from the herbal products. A rational approach to such situations should focus on good resuscitation, symptomatic and supportive care.

Author's contributions: All authors contributed equally to the study.

Funding: This study was self-funded.

Conflicts of interest: Authors have none to declare.

\section{References}

1. Vale FF. Overview of the phytomedicine approaches against Helicobacter pylori. World J Gastroenterol [Internet]. 2014;20(19):5594. Available from: http://www.wignet.com/1007-9327/full/v20/i19/5594.htm

2. Park YL, Canaway R. Integrating Traditional and Complementary Medicine with National Healthcare Systems for Universal Health Coverage in Asia and the Western Pacific. Heal Syst Reform [Internet]. 2019 Jan 2;5(1):24-31. Available from: https://www.tandfonline.com/doi/full/10.1080/23288604.2018.1539058 
3. Satil F, Acar M. Ethnobotanical use of Stachys L. (Lamiaceae) taxa in Turkey. Int J Nat Life Sci [Internet]. 2020 Dec 1;66-86. Available from: https://dergipark.org.tr/en/doi/10.47947/ijnls.736452

4. Polat R, Güner B, Yüce Babacan E, Çakılcıoğlu U. Survey of wild food plants for human consumption in Bingöl (Turkey). Indian J Tradit Knowl [Internet]. 2017;16(3):378-84. Available from: https://www.researchgate.net/profile/ Ugur-Cakilcioglu/publication/317082796 Survey of wild food plants for human consumption in Bingol Turkey/ links/59248835aca27295a8be7eb4/Survey-of-wild-food-plants-for-human-consumption-in-Bingoel-Turkey.pdf

5. Kawarty AMAMA, Behcet L, Çakilcioğlu U. An ethnobotanical survey of medicinal plants in Ballakayati (Erbil, North Iraq). Turk J Botany [Internet]. 2020;44(3):345-57. Available from: https://journals.tubitak.gov.tr/botany/abstract.htm?id=27025

6. Howe E, Keiwkarnka B, Khan MI. Traditional medicine and medicinal plants: utilization, policy and research in Thailand. J public Heal Dev. 2004;2(1):101-18.

7. Peltzer K, Pengpid S, Puckpinyo A, Yi S, Vu Anh L. The utilization of traditional, complementary and alternative medicine for non-communicable diseases and mental disorders in health care patients in Cambodia, Thailand and Vietnam. BMC Complement Altern Med [Internet]. 2016 Dec 8;16(1):92. Available from: http://www.biomedcentral. com/1472-6882/16/92

8. Satyapan N, Patarakitvanit S, Temboonkiet S, Vudhironarit T, Tankanitlert J. Herbal medicine: affecting factors and prevalence of use among Thai population in Bangkok. J Med Assoc Thai [Internet]. 2010 Nov;93 Suppl 6:S139-44. Available from: http://europepmc.org/abstract/MED/21284139

9. Moss TM. Herbal medicine in the emergency department: A primer for toxicities and treatment. J Emerg Nurs [Internet]. 1998 Dec;24(6):509-13. Available from: https://linkinghub.elsevier.com/retrieve/pii/S0099176798700376

10. Palanisamy A, Haller C, Olson KR. Photosensitivity Reaction in a Woman Using an Herbal Supplement Containing Ginseng, Goldenseal, and Bee Pollen. J Toxicol Clin Toxicol [Internet]. 2003 Jan 30;41(6):865-7. Available from: http://www.tandfonline.com/doi/full/10.1081/CLT-120025353

11. Diaconu CC, Dediu GN, lancu MA. Drug-induced arterial hypertension - a frequently ignored cause of secondary hypertension: a review. Acta Cardiol [Internet]. 2018 Nov 2;73(6):511-7. Available from: https://www.tandfonline.com/doi/fu II/10.1080/00015385.2017.1421445

12. Siegel RK. Ginseng Abuse Syndrome: Problems With the Panacea. JAMA [Internet]. 1979 Apr 13;241(15):1614-5. Available from: https://doi.org/10.1001/jama.1979.03290410046024

13. Kwon YE, Oh D-J, Choi HM. Severe asymptomatic hypokalemia associated with prolonged licorice ingestion. Medicine (Baltimore) [Internet]. 2020 Jul 24;99(30):e21094. Available from: https://journals.lww.com/10.1097/ MD.0000000000021094

14. Luo J, Li Z, Wang J, Weng Q, Chen S, Hu M. Antifungal Activity of Isoliquiritin and Its Inhibitory Effect against Peronophythora litchi Chen through a Membrane Damage Mechanism. Molecules [Internet]. 2016 Feb 19;21(2):237. Available from: http://www.mdpi.com/1420-3049/21/2/237

15. Crean AM, Abdel-Rahman S-E-DT, Greenwood JP. A sweet tooth as the root cause of cardiac arrest. Can J Cardiol [Internet]. 2009 Oct;25(10):e357-8. Available from: https://linkinghub.elsevier.com/retrieve/pii/S0828282X09707238

16. Yorgun H, Aksoy H, Şendur MA, Ateş AH, Kaya EB, Aytemir K, et al. Brugada Syndrome with Aborted Sudden Cardiac Death Related to Liquorice-Induced Hypokalemia. Med Princ Pract [Internet]. 2010;19(6):485-9. Available from: https:// www.karger.com/Article/FullText/320309

17. Ernst E. Serious psychiatric and neurological adverse effects of herbal medicines - a systematic review. Acta Psychiatr Scand [Internet]. 2003 Aug;108(2):83-91. Available from: http://doi.wiley.com/10.1034/j.1600-0447.2003.00158.x

18. Shea Y-F, Anthony Chow T-Y, Chiu PK-C, Chan C-K, Mak TWL, Chu L-W. Delirium due to herbal tea contaminated with tropane alkaloid. J Clin Gerontol Geriatr [Internet]. 2012;3(3):110-2. Available from: https://www.sciencedirect.com/ science/article/pii/S2210833512000500

19. Park H, Lim H, Kim H, Kwon Y. Downregulation of Matrix Metalloproteinase-13 by the Root Extract of Cyathula officinalis Kuan and its Constituents in IL-1 $\beta$-treated Chondrocytes. Planta Med [Internet]. 2011 Sep 23;77(13):1528-30. Available from: http://www.thieme-connect.de/DOI/DOI?10.1055/s-0030-1270834

20. Ku Y, Ho Y, Chen C, Ho L, Chang Y. Analysis of N - cis - and N - trans -Feruloyl 3-Methyldopamine in Achyranthes bidentata by HPLC. J Liq Chromatogr Relat Technol [Internet]. 2004 Jan 23;27(4):727-36. Available from: https://www.tandfonline. com/doi/full/10.1081/JLC-120028260

21. Ng THK, Chan YW, Yu YL, Chang CM, Ho HC, Leung SY, et al. Encephalopathy and neuropathy following ingestion of a Chinese herbal broth containing podophyllin. J Neurol Sci [Internet]. 1991 Jan;101(1):107-13. Available from: https:// linkinghub.elsevier.com/retrieve/pii/0022510X91900242 
22. Yang $F$, Yu S, Wang $Y$, Wang R, Jing F. Prospective induction of peripheral neuropathy by the use of Tartarian Buckwheat. J Neurol Sci [Internet]. 2014 Dec;347(1-2):155-8. Available from: https://linkinghub.elsevier.com/retrieve/pii/ $\underline{\text { S0022510X14006352 }}$

23. MacKinney TG, Soti KR, Shrestha P, Basnyat B. Camphor: an herbal medicine causing grand mal seizures. Case Reports [Internet]. 2015 Jun 11;2015(jun11 1):bcr2014209101-bcr2014209101. Available from: https://casereports.bmj.com/ lookup/doi/10.1136/bcr-2014-209101

24. Yates KM, Armour MJ, Pena A. Complementary therapy use amongst Emergency Medicine patients. Complement Ther Med [Internet]. 2009 Aug;17(4):224-8. Available from: https://linkinghub.elsevier.com/retrieve/pii/S0965229909000387 